\title{
ASPECTS REGARDING PARTICLE SIZE DISTRIBUTION AND ENERGY CONSUMPTION WHEN GRINDING HUSKED RICE SEEDS
}

\author{
Gheorghe Voicu, Gabriel-Alexandru Constantin, Elena-Madalina Stefan, \\ Paula Tudor, Mariana Gabriela Munteanu \\ University Politehnica of Bucharest, Romania \\ ghvoicu_2005@yahoo.com,gabriel_alex99@yahoo.com, stefanelenamadalina@gmail.com, \\ paulavoicu85@yahoo.com,munteanumaya@yahoo.com
}

\begin{abstract}
The paper presents part of the results obtained in the experimental investigations regarding the energy consumption in the grinding process of husked rice seeds in grinding machines with a closed chamber of small capacity (knife mill), with the evacuation of the milled material at the end of the milling. The milling indices are analysed and some specifications are made regarding the particle size distribution obtained in the milling process, correlated with the energy consumption when size reduction. Thus, the correlation of the size of the grinded particles, of the grinding index, of the surface increase, of the temperature increase and the energy consumed when shredding with the sample time, as well as other correlations between the specified indices are presented. Several mathematical functions are specified and their regression is made with the experimental data obtained when grinding husked rice seeds. It has been found that the specific energy of grinding increases directly proportional to the time of grinding, but only in the first phase of the process it is consumed to achieve a specific surface growth, in the second phase the surface growth is relatively low. It can be appreciated that the increase of the grinding time above a certain limit produces more intense heating of the material subjected to the grinding and reduced grinding due to the more intense friction between the milled particles and the increase of the heat transfer time. The paper also makes further details regarding the rice grinding indices and graphically presents their variation, some in relation to others.
\end{abstract}

Keywords: rice seeds, grinding, particle size distribution, specific energy, correlation.

\section{Introduction}

On a global scale, rice is the most consumed food for a large part of the human population, especially in Asia. Commercial rice is obtained by peeling paddy rice and then bleaching the seeds by removing the bran layers (polishing) and embryo prior to being consumed as such [1]. Further shredding and polishing of seeds is required only if rice is used as rice flour (as a raw material), either in combination with other cereal flours, or to obtain other rice-based foods.

Given the high nutritional properties of rice, bread made from brown rice flour proves to be attractive to consumers. It was started gradually with the addition of a smaller amount, at first, then bigger and bigger, of rice flour to replace in the recipe the wheat flour, currently reaching bread varieties with $100 \%$ rice flour. More, a wide range of food, including bread, noodles, cakes, cookies, muffins, pre-mix, drinks, vinegar, surimi and artificial meat can use rice flour as a primary ingredient. In this sense, it would be necessary to grind the rice grains with mills that do not damage the starch grains very much, an essential condition in its gelatinization, [2-11]. The milling equipment has a special importance on the functional properties of rice flour [2]. Rice can be ground in dry form, as well as in wet form. Dry grinding causes starch granule damage, by substantially heating the flour, but it is a simple and direct process $[2 ; 5 ; 6]$. Wet milled rice flour contains smaller medium sized starch granules as compared to dry milled samples, but it has a significantly lower protein content and a higher carbohydrate content [5]. If wheat flour mixed with rice flour with a low deteriorated starch content (less than 5\%) is used and an amylose content between 16-20\%, production of gluten-free rice flour bread does not differ much from how wheat flour bread is made.

It must be mentioned, still, that the grinding method significantly affects the damaged starch content, the state of the starch granule, gelatinization temperature and enthalpy of absorption of rice flour. In this regard, rice flour, wet grinded, has a low content of damaged starch and a higher integrity of the starch granules from which a better rice bread is obtained, gluten free [7-9]. Grain milling, in order to transform it into flour, involves the application of complex mechanical stresses (impact, shear, crushing, rubbing) on seeds and seed particles in grinders of different constructions. Grist particle size distribution, dimensional limits, average particle size and grinding energy consumption are influenced by the physical-mechanical properties of the material subjected to grinding, including the variety of the species, of the type and characteristics of the grinder machine, as well as the work regime 
adopted [2; 8; 10-12]. Grinding can be done with the help of hammer mills, roller mills, pin mills or fluid-energy mills [2].

In hammer mills, the feed material is fed into a grinding chamber, in which a high speed rotor, having more hammers with equal distances between them, grind the material on its periphery until the obtained particles are small enough to pass through a sieve disposed outside the grinding chamber [2].

The energy consumption for grinding cereals is influenced by the type of material used, moisture content, size and type of hammers, apertures of sieve etc. [13].

With grinding machines, used in laboratory, with fixed blades (or knife), such as household coffee grinders (knife mill), particle grinding is performed, mainly, by the shocks applied to them by the rotor blades, but also by the impact of the particles with the interior walls of the grinding chamber or by rubbing with them. This type of device is used, in particular, for laboratory determinations related to, either in humidity or for other determinations (as we mentioned earlier), with the results obtained for grinding machines of larger dimensions but of similar construction.

At these devices, grinding is performed in batch, and the material subjected to grinding remains inside the grinding chamber as long as the operator wants, being evacuated only at the end of the grinding process, as opposed to the continuous flow grinders provided with sieves, at which the grist is evacuated continuously, as the particles reach dimensions below the sieve apertures with which the machine is equipped.

It can be said that granulation of the grist is smaller as the time of grinding is higher. Also, the specific energy consumption when grinding increases in proportion to the grinding time and the average dimensions of the grist particles. However, these claims must be supported by experimental research, especially in laboratory conditions, which is also the objective of the present work.

Grinding, in itself, is not a difficult operation, it is made with several types of mills, but each type of machine leads to a specific characteristic energy consumption. Therefore, the grinding is done both to obtain rice flour, as well as for the purpose of obtaining information on the condition of rice seeds (humidity, energy consumption, granularity, damaged starch contents, other types of chemical analyses, etc.).

Around the world, researchers frequently use a series of mathematical expressions to describe particle size distribution and to make a correlation between the amount of grist and the average particle size. These expressions, although similar, differ depending on the equipment used, by its constructive and functional characteristics, but also by the physical properties of the material $[12 ; 14]$.

To this end, the paper aims to convey to readers and specialists in the field of rice grinding (whether they are millers, technologists or laboratory analysts) additional information on the specific resistance to grinding of rice seeds, in order to transform it into flour, using a laboratory knife mill, specifying the dimensional limits of the grinded particles and their size distribution, in correlation with the energy consumed in the process, with the specific surface, with the increase in temperature during the process and with the test time.

\section{Materials and methods}

Both globally and in Romania, experimental researches were conducted on the grinding degree of grains, at the fineness of the machine obtained and the energy consumed in the process, however, the physico-mechanical characteristics of the material subjected to grinding differ from one area to another, from device to device, being influenced by the characteristics of the grinding machines [2; 10-12].

Studies on the physical, physicochemical and mechanical properties of cereal seeds and intermediate grist products are carried out by many researchers in order to obtain high yields and savings in energy consumption.

Thus, it is known that the index of the grinding degree $\lambda$ is given by the relation $[2 ; 12]$ :

$$
\lambda=\frac{D}{d}=\frac{S_{f}}{S_{i}},
$$


where $D, d$-average equivalent dimensions of the particles subject to grinding, respectively of the grinded ones;

$S_{i}, S_{f}$ - outer surface of particles introduced into the process and those obtained.

During the grinding process, a specific surface growth takes place, the size of which depends on the grist granulation. At the same time, the specific outer surface of the newly formed particles can be estimated, if the density of the material $\rho$ is known and the average equivalent diameter of the particles $d_{m}$, using the relation, $[2 ; 12]$ :

$$
S_{e . m}=\frac{6}{\rho \cdot d_{m}},\left(\mathrm{~m}^{2} \cdot \mathrm{kg}^{-1}\right)
$$

where $d_{m}$ - determined by particle size distribution, using the relation

$$
d_{m}=\frac{\sum_{i=0}^{n} p_{i} d_{i}}{100},
$$

where $p_{i}$ represents the percentage of material on the $i$ sieve of the classifier;

$d_{\mathrm{i}}$ - average diameter of the fraction $i\left(d_{i}=\left(c_{i}+c_{i+1}\right) / 2\right)$;

$c_{i}, c_{i+1}-$ dimensions if the sieve aperture fits the fraction $i[2 ; 10]$.

The energy consumed in the grinding process has various estimation relations [2] and depends on the nature and humidity of the grinded material, its structure and internal state, the characteristics of the effort applied (size, duration, speed), etc.

In addition, the particle size distribution and the degree of starch damage are the two key factors that affect the physicochemical properties of rice flour and, in turn, obtaining flour specific to a certain product $[9 ; 14]$.

Extra Deroni Camolino rice seeds were used for experimental determinations, from trade, husked and processed, packed in polypropylene foil and marketed by the company Bitar International srl, Bucharest, with the nutritional characteristics inscribed on the packaging: $249 \mathrm{kcal}$ per $100 \mathrm{~g}, 7 \%-$ protein, $78 \%$ - carbohydrates, $1 \%$ - fats, having moisture (determined in the laboratory) of 13.89$14.32 \%$ (wet basis) to seeds and $11.99-12.32 \%$ (w.b.) at grist.

The equipment used consisted of a laboratory grinder, Grindomix GM200 (with rotor with two fixed knives, at $3000 \mathrm{rpm}$ ), RETSCH; a digital multimeter M110G with thermocouple, a Siemens active electricity meter with an accuracy of $0.1 \mathrm{~W} \cdot \mathrm{h}$, for determining the energy consumption when grinding. Also, a digital chisel was used (precision $0.01 \mathrm{~mm}$ ), a stopwatch, a sieve shaker Analysette 3 Spartan (Fritsch), a Kern electronic balance with the precision of $0.1 \mathrm{~g}$, a moisture analyser Kern RH 120-3 with IR and a pycnometer of $25 \mathrm{ml}$.

$50 \mathrm{~g}$ of rice seeds were grinded using the grinder, working times being 10, 20, 30, 40, 50 and $60 \mathrm{~s}$.

At the beginning and immediately at the end of the grinding, the initial seed temperature and the resulting grist temperature were determined.

The obtained grist was subjected to the tests of particle size distribution, all samples with the same set of sieves, at amplitude of $2 \mathrm{~mm}$ oscillation and a sifting time of 3 minutes. On several samples (properly combined and homogenized) analyses were performed to determine the density of the material using the pycnometer, using xylene as a working liquid with a density of $860 \mathrm{~kg} \cdot \mathrm{m}^{-3}$, according to the methodology presented in [12]. Thus, the average density of the material was approx. $1352.3 \mathrm{~kg} \cdot \mathrm{m}^{-3}$, which also corresponds to the density obtained on seed samples.

The values of the equivalent average diameter of the grinded particles were determined by calculation, using the relation (3), and those of the specific outer surface through the relation (2).

Average equivalent dimensions and the specific external surface of the seeds subjected to grinding were obtained after measurements on the three dimensions of the seeds, made with a digital calliper on 100 seeds. Their values were within the limits: $l=4.9-5.6 \mathrm{~mm} ; b=2.4-2.9 \mathrm{~mm} ; c=1.6-2.1 \mathrm{~mm}$, classified as medium-sized seeds [14]. By approximating the volume of seeds with that of an ellipsoid with axes $l, b$ and $c$, were obtained for their equivalent diameter values of 2.71-3.19 mm, the average value being $2.95 \mathrm{~mm}$. 
With the help of the active electricity meter the energy consumption was determined, with no load and at load, for each sample of the material, corresponding to the respective sample time.

\section{Results and discussion}

Our analyzes were mainly performed only up to the characteristic dimensions of semolina flour, specifying the limits of the ginding machine, showing a final size of $300 \mu \mathrm{m}$, but for flour specific to bakery products the average particle size should be significantly smaller, respectively $140-150 \mu \mathrm{m}$, [14]. These dimensions can drop to average values of about $55 \mu \mathrm{m}$ or smaller, if wet or semi-dry grinding is used [3; 4].

In Table 1 and Table 2 the results obtained from the experimental determinations are summarized, both in the preliminary phase and after the calculations made with the relations presented.

Also, in Fig. 1 charts of average equivalent diameter are presented, temperature increases, the grinding index $\lambda$, specific grinding energy and an increase of the specific surface area, depending on the grinding time, as well as temperature increases depending on the diameter of the grinded particles.

To express through mathematical relations the variation of grinding specific energy consumption $E$, in relation to the other parameters of the grinding, linear and nonlinear regression of the experimental data with several types of functions was performed. Regression analysis was performed using the programs MicroCall Origin 8.0 and TableCurve, in Fig. 2 are presented the charts of variation of the specific energy with the other parameters of the process, as well as the regression curve of the function that best correlates with the experimental data. The set of functions used in the regression are presented in Table 3 together with the values of the coefficients of the obtained equations and of the correlation coefficient $\mathrm{R}^{2}$.

The type of relationships used is in accordance with the literature in the field of grain grinding [8;12], being universally accepted that the variation of energy in relation to the other parameters of the process is an exponential one. However, several types of functions that approximate experimental data have been used, accepting that the coefficients of the expressions obtained are in correlation with the type of the mill and the characteristics of the material subjected to grinding.

Experimental and calculated results, obtained by grinding seeds of rice

Table 1

\begin{tabular}{|c|c|c|c|c|c|c|c|}
\hline \multirow{2}{*}{$\begin{array}{c}\text { Working } \\
\text { time, } s\end{array}$} & \multicolumn{2}{|c|}{$\begin{array}{c}\text { Grinding energy } \\
\text { Wh·kJ } \mathbf{k J}^{-1}\end{array}$} & \multirow{2}{*}{$\begin{array}{c}\text { Initial } \\
\text { temp./Final } \\
\text { temp., } \\
{ }^{\circ} \mathrm{C}\end{array}$} & \multirow{2}{*}{$\begin{array}{c}\text { Specific } \\
\text { surface } \\
S_{e . m}, \mathbf{m}^{2} \cdot \mathbf{k g}^{-1}\end{array}$} & \multirow{2}{*}{$\begin{array}{c}\text { Particle } \\
\text { dimension, } \\
d_{m}, \mathrm{~mm}\end{array}$} & \multirow{2}{*}{$\begin{array}{c}\text { Index } \\
\lambda=D / d_{m}\end{array}$} & \multirow{2}{*}{$\begin{array}{c}\text { Specific } \\
\text { energy } \\
E_{m}, \mathbf{k J} \cdot \mathbf{k g}^{-1}\end{array}$} \\
\hline & $\begin{array}{l}\text { Under } \\
\text { load }\end{array}$ & $\begin{array}{c}\text { In } \\
\text { emptiness }\end{array}$ & & & & & \\
\hline 0 & $0 / 0$ & $0 / 0$ & $12 / 12$ & 1.580 & 2.950 & 1 & 0 \\
\hline 10 & $0.3 / 1.08$ & $0.16 / 0.576$ & $12 / 17$ & 6.270 & 0.744 & 3.97 & 10.08 \\
\hline 20 & $0.6 / 2.16$ & $0.32 / 1.152$ & $12 / 24$ & 8.420 & 0.554 & 5.33 & 20.16 \\
\hline 30 & $1.1 / 3.96$ & $0.48 / 1.728$ & $14 / 28$ & 10.113 & 0.462 & 6.40 & 44.64 \\
\hline 40 & $1.4 / 5.04$ & $0.64 / 2.304$ & $13 / 33$ & 12.269 & 0.380 & 7.78 & 54.72 \\
\hline 50 & $1.7 / 6.12$ & $0.80 / 2.880$ & $14 / 37$ & 12.526 & 0.373 & 7.92 & 64.8 \\
\hline 60 & $2.0 / 7.20$ & $0.95 / 3.420$ & $15 / 42$ & 12.665 & 0.369 & 8.01 & 75.6 \\
\hline
\end{tabular}

From the analysis of the presented data, an increase of the temperature of the grinded material is observed, compared to the initial temperature of the seeds, which is greater if the grinding time increases; as well as the increase of specific surface area in the process, which also grows over time.

Thus, the temperature difference increases from $5{ }^{\circ} \mathrm{C}$, for a grinding time of 10 seconds, to a difference of $27^{\circ} \mathrm{C}$, for a grinding time of 60 seconds, the variation being approximately linear. Regarding the specific surface of the particles, it grows from approx. $1.58 \mathrm{~m}^{2} \cdot \mathrm{kg}^{-1}$, for seeds, to $6.27 \mathrm{~m}^{2} \cdot \mathrm{kg}^{-1}$, for grist particles grinded for $10 \mathrm{~s}$, respectively at about $12.67 \mathrm{~m}^{2} \cdot \mathrm{kg}^{-1}$, for the grist obtained after $60 \mathrm{~s}$ of grinding. 

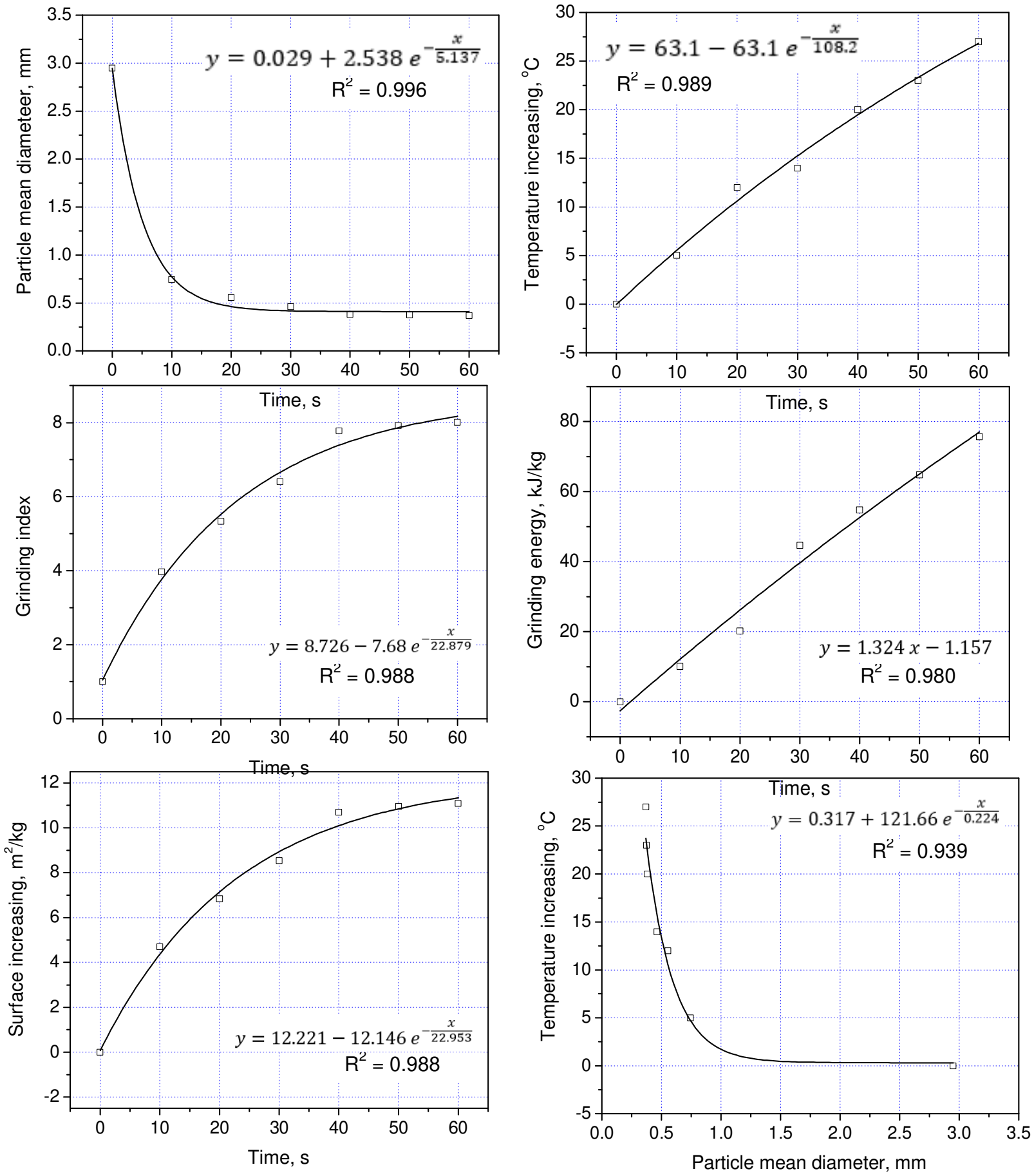

Fig. 1. Variation of the grinding parameters with the sample time, respectively the temperature variation of the grist with the particle diameter

Table 2

Particle size distribution for grinded rice seeds

\begin{tabular}{|c|c|c|c|c|c|c|}
\hline $\begin{array}{c}\text { Mesh size, } \\
\mathbf{~ m m}\end{array}$ & \multicolumn{7}{|c|}{ Percents on shaker sieves (\%), depending on grinding time of the sample } \\
\cline { 2 - 7 } & $\mathbf{1 0} \mathbf{~ s}$ & $\mathbf{2 0} \mathbf{~ s}$ & $\mathbf{3 0} \mathbf{~ s}$ & $\mathbf{4 0 ~ s}$ & $\mathbf{5 0} \mathbf{~ s}$ & $\mathbf{6 0 ~ s}$ \\
\hline 0 & 5.0 & 5.7 & 8.4 & 10.3 & 9.9 & 10.2 \\
\hline 0.200 & 4.7 & 7.7 & 10.2 & 13.1 & 14.0 & 15.2 \\
\hline 0.315 & 7.3 & 11.5 & 12.1 & 13.8 & 13.9 & 12.3 \\
\hline 0.500 & 6.8 & 10.2 & 9.2 & 8.5 & 8.1 & 7.5 \\
\hline 0.710 & 9.1 & 9.5 & 7.8 & 3.8 & 3.8 & 4.4 \\
\hline 1.000 & 17.1 & 5.1 & 2 & 0.5 & 0.3 & 0.4 \\
\hline
\end{tabular}



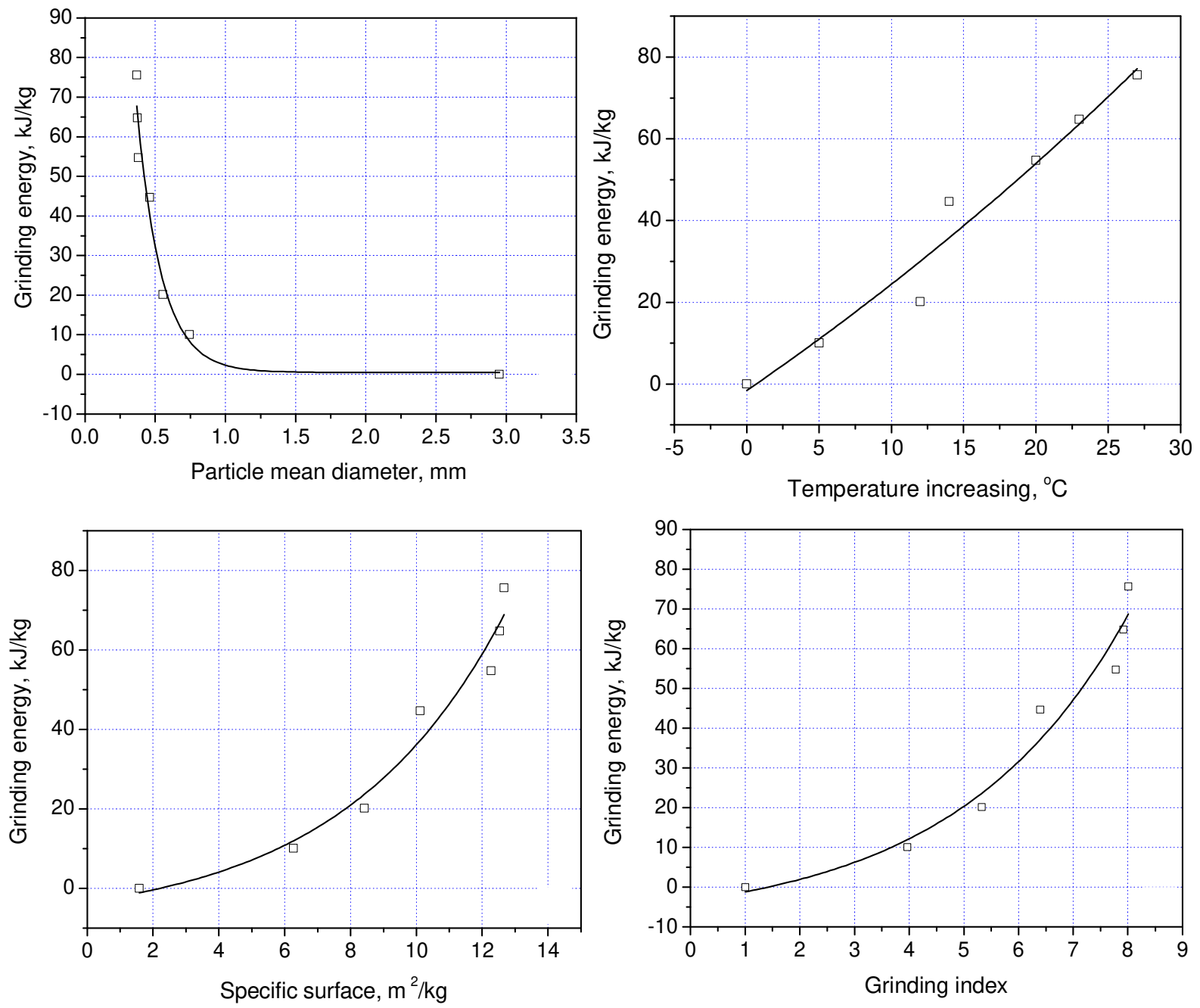

Fig. 2. Energy variation and correlation with the other parameters of the grinding process

It can be appreciated that the increase in temperature is due to both the friction that occurs between the particles and the rotor blades of the device and also to the internal stresses inside the particles that appear with the application of the knives stresses on them.

Index $\lambda$, of appreciation of the degree of particle grinding also increases with the time of grinding, variation having the same allure as for the specific surface growth, from about $3.97 \mathrm{~m}^{2} \cdot \mathrm{kg}^{-1}$ for a grinding time of $10 \mathrm{~s}$, at about $8.01 \mathrm{~m}^{2} \cdot \mathrm{kg}^{-1}$, for a grinding time of $60 \mathrm{~s}$.

Regarding the specific energy in the grinding process, its variation is approximately linear with the working time, growing from $10.08 \mathrm{~kJ} \cdot \mathrm{kg}^{-1}$ for a grinding time of $10 \mathrm{~s}$, to about $75.6 \mathrm{~kJ} \cdot \mathrm{kg}^{-1}$ for a grinding time of $60 \mathrm{~s}$.

It is worth noting, however, that the equivalent diameter of the material particles decreases sharply in the first $10 \mathrm{~s}$ (from $2.95 \mathrm{~mm}$ to $0.744 \mathrm{~mm}$ ), then within the time range from $10 \mathrm{~s}$ to $60 \mathrm{~s}$ its variation is relatively small (from $0.744 \mathrm{~mm}$ to $0.369 \mathrm{~mm}$ ), for an increase of the grinding time from $40 \mathrm{~s}$ to $60 \mathrm{~s}$ its variation is practically insignificant (from $0.38 \mathrm{~mm}$ to $0.369 \mathrm{~mm}$ ).

The same phenomenon occurs with regard to the grinding index or the increase of specific surface area, which leads to the conclusion that for this time interval the energy is consumed especially for the increase of the temperature of the grist, increasing over this range from $20^{\circ} \mathrm{C}$ to $27^{\circ} \mathrm{C}$ (from $30 \mathrm{~s}$ to $60 \mathrm{~s}$, the difference being of $13{ }^{\circ} \mathrm{C}$, at a sample weight of $50 \mathrm{~g}$ of material).

If we refer to the increase of temperature according to the equivalent average diameter of the grist particles, as shown in the corresponding chart (Fig. 1), this increases almost sharply if the equivalent diameter drops from $0.462 \mathrm{~mm}$ to about $0.369 \mathrm{~mm}$. 
Regression function coefficients and $\boldsymbol{R}^{2}$ coefficient values

\begin{tabular}{|c|c|c|c|c|}
\hline \multirow{2}{*}{ Regression function* } & \multicolumn{3}{|c|}{ Coefficients of regression functions } & \multirow{2}{*}{$\begin{array}{c}\text { Correlation } \\
\text { coefficient } R^{2}\end{array}$} \\
\hline & $a$ & $b$ & $c$ & \\
\hline \multicolumn{5}{|c|}{$E=f\left(d_{m}\right)$} \\
\hline$y=a+b \cdot e^{-x / c}$ & 0.450 & 544.215 & 0.176 & 0.966 \\
\hline$y=1 /\left(a+b \cdot e^{x}\right)$ & -0.119 & 0.092 & & 0.961 \\
\hline$y=a+b \cdot x^{c}$ & -0.989 & 5.546 & -2.529 & 0.965 \\
\hline \multicolumn{5}{|c|}{$E=f(\Delta T)$} \\
\hline$y=a+b \cdot x^{c}$ & -0.777 & 1.733 & 1.153 & 0.964 \\
\hline$y=a+b \cdot x$ & -3.322 & 2.896 & - & 0.960 \\
\hline$y=a \cdot x^{b}$ & 0.080 & 1.175 & - & 0.964 \\
\hline \multicolumn{5}{|c|}{$E=f\left(S_{s p}\right)$} \\
\hline$y=\exp (a+b \cdot x)$ & 0.882 & 0.267 & - & 0.949 \\
\hline$y=a+b \cdot x^{3}$ & 1.772 & 0.034 & - & 0.955 \\
\hline \multicolumn{5}{|c|}{$E=f(\lambda)$} \\
\hline$y=\exp (a+b \cdot x)$ & 0.908 & 0.415 & - & 0.956 \\
\hline$y=a+b \cdot x^{3}$ & 2.033 & 0.130 & - & 0.961 \\
\hline$y=a+b \cdot x^{c}$ & -0.991 & 0.358 & 2.529 & 0.964 \\
\hline$y=a \cdot \log \left(x^{3}\right)+(x-1)$ & -32.342 & 22.067 & - & 0.964 \\
\hline$y=a \cdot \ln (x)^{b}+c(x-1)$ & 2.424 & 4.615 & -0.512 & 0.966 \\
\hline$y=a \cdot(x-1)$ & 8.525 & - & - & 0.841 \\
\hline$y=a \cdot\left(x^{1 / 2}-1\right)$ & 20.492 & - & - & 0.875 \\
\hline$y=[a+b \cdot x \cdot \ln (x)]^{2}$ & 0.950 & 0.441 & - & 0.964 \\
\hline$y=\exp \left[a+b \cdot \ln (x)^{2}\right]$ & 1.125 & 0.717 & & 0.960 \\
\hline
\end{tabular}

* in relations $y$ represents $E$, and $x$ the independent parameter $\left(d_{m}, \Delta T, S_{s p}\right.$ or $\left.\lambda\right)$

Therefore, it should be specified that during the grinding process the material is arranged on the outer edge of the rotor with knives, returning very little to their area of action if the device is not agitated. This phenomenon leads to a strong variation of the process parameters in the first phase of grinding, followed by a slow variation of them. This should make the manufacturers of such devices think to try to make machines that allow a more pronounced agitation of the material during the grinding process to reduce the time in which the material can be brought from an initial size of the grist to a smaller final size.

From Table 3 it is found that the variation of the specific energy at grinding $E$ with respect to the equivalent average diameter of the grinded particles is best estimated by an exponential equation of the type, as it results from other specialized papers $[8 ; 12]$ :

$$
E=0.45+544.2 \exp \left(-\frac{d_{m}}{0.176}\right)
$$

with a degree of correlation with the experimental data $R^{2}=0.966$ (about $97 \%$ ).

Also, the variation of the specific energy $E$ according to the specific surface of the grinded particles is best estimated (with a correlation $R^{2}=0.949$ ) by an exponential equation of the type:

$$
E=\exp \left(0.882+0.267 \cdot S_{s p}\right),
$$

The expressions obviously show that it is not only the average particle size or the specific surface that influence the value of the energy consumed in the process of grinding rice, but also the type of the mill or the physical-mechanical properties of the material, expressed by the values of the expression coefficients. For rice seeds and the knife mill used in the experiments presented in the paper, the values of these coefficients are those specified in relations (4) and (5). 


\section{Conclusions}

In the process of grinding rice seeds using grinding machines with fixed blades and low capacity (knife mills) the grinded particle size has a marked decrease only in the first 10-20 seconds, after which their reduction is less significant due to the way the grinding process is carried out (at the end of the knife and not along their entire length).

The arrangement of the material towards the outside of the rotor of the grinding machine causes the dimensional parameters of the grist and the energy consumed to have sudden variations in the first part of the test time, decreasing and maintaining relatively steady in the second part.

The specific grinding energy increases directly in proportion to the grinding time, but only in the first phase of the process it is consumed to achieve a specific surface growth, in the second phase the surface growth is relatively low. For operating times of up to one minute, the specific grinding energy had values below $75 \mathrm{~kJ} \cdot \mathrm{kg}^{-1}$, at an average particle size of about $0.370 \mathrm{~mm}$ and the index of the grinding degree $\lambda=8$.

It can be appreciated that the increase of the grinding time over a certain limit produces a more intense heating of the material subjected to grinding, reduced grinding due to the more intense friction between the fine grist particles and increasing heat transfer time.

The mathematical expression of the energy consumed according to the other indicators of appreciation of the grinding process is necessary for a quick estimation of it before possibly reconfiguring the working method or functional parameters of the machine.

A reconfiguration of the construction and operation of such grinders, with knives and a closed grinding chamber (without sieve for evacuation of grist), would be necessary to reduce the energy consumption and correlate it with the dimensional parameters of the grinder and with the increase of temperature during the grinding process.

\section{References}

[1] Caringal B.K.M., Dela Rosa Z.S., Maan K.V.R., Camello N.C., Design and development of rice milling and grinding machine, EPH - International Journal of Science and Engineering, 2(8), August 2016, Paper-2.

[2] Kim M.H., Review on rice flour manufacturing and utilization, Journal of Biosystems Engineering, 38(2), 2013, pp. 103-112.

[3] Gao X.-X., Tong L.-T., Zhong K., Liu L.-Y.,. Zhou S.-M, Wang L., Effect of milling processes on quality of rice flour, Modern Food Science and Technology, 31(1), 2015, pp. 194-199, DOI: 10.13982/j.mfst.1673-9078.2015.1.034

[4] Leewatchararongjaroen J., Anuntagool J., Effects of dry-milling and wet-milling on chemical, physical and gelatinization properties of rice flour, Rice Science, 23(5), 2016, pp. 274-281.

[5] Araki E., Ashida K., Aoki N., Takahashi M., Hamada S., Characteristics of rice flour suitable for the production of rice flour bread containing gluten and methods of reducing the cost of producing rice flour, Japan Agricultural Research Quarterly, 50(1), 2016, pp. 23-31.

[6] Joy E.-E., Ledogo N., The effect of variety and processing methods on the functional and chemical properties of rice flour, International Journal of Nutrition and Food Sciences, 5(1), 2016, pp. 80-84, DOI: 10.11648/j.ijnfs.20160501.22.

[7] Tong Wu, Lili Wang, Yan Li, Haifeng Qian, Liya Liu, Litao Tong, Xianrong Zhou, Li Wang, Sumei Zhou, Effect of milling methods on the properties of rice flour and gluten-free rice bread panel, LWT, Vol. 108, 2019, pp. 137-144.

[8] Fang Q., Haque E., Spillman C.K., Reddy P.V., Steele J.L., Energy requirements for size reduction of wheat using a roller mill, Transactions of the ASAE, 41(6), 1998, pp. 1713-1720.

[9] Kamst G.F., Bonazzi C., Vasseur J., Bimbenet J.J., Effect of deformation rate and moisture content on the mechanical properties of rice grains, Transactions of the ASAE, vol. 45(1), 2002, pp. $145-151$.

[10] Voicu Gh., Casandroiu T, Tutuianu G.-D., Aspects regarding the granulometrical properties of grinded wheat particles, International Symposium „Euro-Aliment 2003”, Galati, Romania, 2003, Academica publishing House, 201-205 (in Romanian). 
[11]Drocas I., Marian O., Ovidiu R., Molnar A., Muntean M., Determination of specific energy consumption and grain size for corn grinding using the hammer mill MB7.5, Bulletin USAMV, series Agriculture, 71(2), 2014, pp. 381-382.

[12] Kim M.H., Review on Rice Flour Manufacturing and Utilization, Journal of Biosystems Engineering, 2013, 38(2), pp. 103-112, DOI: 10.5307/JBE.2013.38.2.103.

[13]Fofana M., Futakuchi K., Manful J.T., Bokossa Yaou I., Dossou J., Bleoussi R.T.M., Rice grain quality: A comparison of imported varieties, local varieties with new varieties adopted in Benin, Food Control, 22, 2011, pp. 1821-1825.

[14] Thiranusornkij L., Thamnarathip P., Chandrachai A., Kuakpetoon D., Adisakwattana S., Physicochemical Properties of Hom Nil (Oryza sativa) Rice Flour as Gluten Free Ingredient in Bread, Foods 2018, 7, 159; 13 p, DOI: 10.3390/foods7100159. 